\title{
Design of a Taxation System to Promote Electric Vehicles in Singapore
}

\author{
Seng Tat Chua and Masaru Nakano \\ The Graduate School of System Design and Management, Keio University \\ Kyosei Building, 4-1-1, Hiyoshi, Kohoku-ku, Yokohama, Kanagawa, 223-8526, Japan \\ c.sengtategmail.com, nakanodsdm.keio.ac.jp
}

\begin{abstract}
Electric vehicles offer a potential low-carbon alternative to today's gasoline-powered vehicles. In line with global trends, Singapore has expressed interest in promoting electric vehicles on its shores. This paper investigates the effects of taxation, namely tax rebates and carbon taxes, on the penetration of electric vehicles in Singapore. A consumer vehicular preference model was constructed using the logit model, and the effects on the economy determined through an input-output analysis. Multi-objective optimization is then used to find the optimal tax rate. Results indicate that a tax rebate minimizes the negative impact on the economy at a low penetration rate of electric vehicles, whereas a carbon tax minimizes the negative impact on GDP at a high penetration rate of above $60 \%$.
\end{abstract}

Keywords: Electric Vehicles, Sustainable Manufacturing, Socio-Technical Approach, Taxation.

\section{Introduction}

A holistic and socio-technical approach is needed to design a green society with clean energy vehicles (CEVs) in terms of extended social responsibility [1]. Sustainable manufacturing is defined in Nakano [2] as two concepts of 'manufacturing for society, mainly environmental issue' and 'sustainability of manufacturing sector'. Today, automakers are competing globally to develop CEVs. Manufacturing technologies are required that can reduce manufacturing costs and recycle valuable material. Service-oriented architectures, such as the used-battery business, have been developed to encourage consumers to accept EVs. Many national and local governments offer tax incentives to consumers to buy CEVs, and give subsidies to manufacturers to develop technologies such efficient batteries specifically designed for CEVs. This paper focuses on a taxation system to promote electric vehicles.

An integral part of Singapore's electric vehicle test-bedding program is positioning Singapore as a "Living Laboratory." The concept envisions Singapore as a place for companies to leverage its public infrastructure and experience systems-level integration for researching, developing, and testing innovative solutions for electric vehicles in a real environment with human activities. 
This research proposes an optimal taxation rate to increase the adoption rate of electric vehicles while considering the tradeoffs between gains in environmental benefits and reductions in GDP, due to decreased output in the petroleum industry as a result of an increase in the share of electric vehicles.

Two types of taxation will be investigated. The first is a tax rebate levied upon the purchase of an electric vehicle to lower the initial price of an electric vehicle relative to that of a conventional car. By lowering the automobile taxes of electric vehicles through the tax rebate, it is hoped that the price competitiveness of electric vehicles will increase, influencing consumers to make the greener purchase. The second taxation is a carbon tax levied on the fuel used by vehicles during the utilization phase. Taxation during the utilization phase implies that a tax on carbon emissions will be imposed on gasoline in case of a conventional car and electricity in case of an electric vehicle. The carbon tax will vary according to the amount of carbon dioxide emitted, based on the well-to-wheel (WtW) emissions of a vehicle. Because WtW carbon dioxide emissions of conventional cars are higher than that of electric vehicles, consumers will pay a higher carbon tax for conventional cars. The hypothesis is that by further increasing the running cost of conventional gasoline-powered cars through the carbon tax, the price competitiveness of electric vehicles will increase, causing consumers to choose electric vehicles over conventional cars.

\section{Literature}

\subsection{Singapore and Other Countries}

In larger countries such as the United States, Europe and Japan, there has been much interest in past research on the general diffusion process of alternative drive-train technologies [3, 4]. As the intention to promote electric vehicles is a recent development in Singapore, conventional researches based on Singapore as a subject of study have not yet been conducted. There has been largely qualitative research on the success of regulatory and economic instruments in urban environmental policy in Singapore [5]. In quantitative research, areas of focus include modeling of the number of cars in Singapore and comparisons between welfare effects of ownership taxes and usage taxes on cars [6, 7]. However, the effects of the introduction of taxes on the economy and environment have not been reported in conventional studies. In addition, promotion of electric vehicles through taxation has not been studied.

\subsection{Macro and Micro Modeling}

Traditional approaches to model vehicle diffusion can be largely categorized into macro and micro modeling. Macro modeling seeks to explain the aggregate economy whereas micro modeling refers to the representation of the behavior of consumers or smaller entities comprising individuals. While macro models seek to determine the impact on the economy and inter-relations between different sectors of the economy [8], they are founded on the assumption of the price rationality of consumers and do 
not allow for the construction of a vehicular preference model that includes characteristics beyond cost considerations. In contrast, while micro models are concerned with the vehicular preferences of consumers and the penetration rate of electric vehicles [9], there is insufficient treatment of the effects on the aggregate economy such as industrial structure, GDP, and the interconnections between sectors of the economy. A study on carbon taxation has been studied by using life cycle assessment [10], but GDP is not considered.

This paper thus seeks to harness strengths and compensate for the weaknesses of both macro and micro modeling approaches by combining both macro and micro approaches. The logit model based on past vehicle population data is used to determine vehicular preferences of consumers and predict the share of electric vehicles, while the impact of the proposed taxation on the economy is measured using an input-output analysis.

\subsection{Tax Rebate and Carbon Tax}

Conventional studies [8, 9] have primarily focused on the effects of one particular type of taxation, and merits and demerits of different types of tax policies have not been compared. In addition, while conventional researches have examined the effects of a tax on gasoline, the effects of a carbon tax levied on the "fuel" used by a vehicle, i.e., electricity taxed in case of electric vehicles, have not been studied. This paper, therefore, compares the effects of a tax rebate and a carbon tax based on Well-toWheel (WtW) carbon dioxide emission calculations.

\section{$3 \quad$ Methodology}

The effect of taxation on the share of electric vehicles up to 2020 will first be determined using a consumer vehicular preference model, by considering a projected decrease in the cost of electric vehicles and rising oil prices. The consumer vehicular preference model will be constructed using the logit model, based on past vehicle population data. The consumer utility function described below depends on two variables, i.e., lifecycle cost (LCC) or total ownership cost of a vehicle and previous year's vehicle share (VS). EV and GV denote electric vehicle and gasoline vehicle respectively.

$$
\begin{gathered}
f_{k}=\alpha \mathrm{LCC}_{\mathrm{k}}+\beta \mathrm{VS}_{\mathrm{k}} \\
k \in\{E V, G V\} .
\end{gathered}
$$

Vehicular population data of Singapore, categorized according to type of fuel, released by the Land Transport Authority was used to determine the consumer vehicular preference model. The data from 2006 to 2010 was used for the purpose of this paper. The share of vehicles $S_{k}$ is then calculated as follows.

$$
S_{k}=\exp \left(f_{k}\right) / \sum_{k=1}^{n} \exp \left(f_{k}\right)
$$


The impact on the economy is then measured using the input-output analysis by the following equation.

$$
X=(I-A)^{-1} F
$$

where $X, A$, and $F$ refer to domestic product, input coefficient matrix, and final demand, respectively. The 2005 benchmark Input-output tables have been compiled to analyze 136 industrial sectors and commodities [11]. For the purpose of this study, the tables that have been aggregated into 12 industrial sectors and commodities are used. Multi-objective optimization is used to determine the optimal tax that minimizes the adverse effect on the economy and maximizes the reduction in carbon dioxide emissions, based on the following equation:

$$
\begin{array}{cl}
\max _{t} & w_{1} \Delta E C O N(t)+w_{2} \Delta C O 2(t) \\
& \text { subject to } O \leq t \leq T_{\max },
\end{array}
$$

where $\triangle E C O N$ is the increase in gross national output, $\triangle C O 2$ is the reduction in carbon dioxide emissions, $t$ is the tax rate, and $T_{\max }$ is the maximum tax rate when $99 \%$ electric vehicle share is reached. $\triangle E C O N$ and $\triangle C O 2$ are functions of taxation rate, and their equations are determined by fitting trend lines to the data obtained. The weights on GDP and $\mathrm{CO} 2$ are denoted by $w_{1}$ and $w_{2}$ respectively. As shown in Table $1, w_{1}$ will take on a range of values from 0 to 1 , and $w_{2}$ will be calculated using the relation $w_{2}=1-w_{1}$. The optimal taxation rate for the different combinations of weights will be determined using the SOLVER tool in Microsoft Excel.

Table 1. Combination of weights for determination of optimal tax rate

\begin{tabular}{|c|c|}
\hline Weight on GDP $\left(\boldsymbol{w}_{\boldsymbol{1}}\right)$ & Weight on CO2 $\left(\boldsymbol{w}_{\boldsymbol{2}}\right)$ \\
\hline 0 & 1 \\
\hline 0.1 & 0.9 \\
\hline 0.2 & 0.8 \\
\hline 0.3 & 0.7 \\
\hline 0.4 & 0.6 \\
\hline 0.5 & 0.5 \\
\hline 0.6 & 0.4 \\
\hline 0.7 & 0.3 \\
\hline 0.8 & 0.2 \\
\hline 0.9 & 0.1 \\
\hline 1 & 0 \\
\hline
\end{tabular}




\section{$4 \quad$ Results}

\subsection{Effect of Tax Rebate}

The cost of vehicles in Singapore is given by the sum of its Open Market Value (OMV), Registration Fee (\$140), Additional Registration Fee (100\% of OMV) and Excise Duty (20\% of OMV). Figure 1 shows that as the amount of the tax rebate for only EVs increases, the share of EVs increases. In the absence of any form of taxation, only a $1.4 \%$ share of electric vehicles will be reached in 2020 , even after considering the fall in battery costs and rising oil prices. To reach $30 \%$ share by 2020 , the amount of tax rebate needed is approximately $53 \%$ of OMV, which denotes the cost of the vehicle.

In determining the industrial structure, no change in final demand was assumed in the retail trade of vehicles or petrol kiosks/ charging stations. This is because the decrease in demand for petrol-related services will be compensated by the increase in demand for electric vehicle-related services. The trend captured in 2020 is taken to be representative of other years as well. Note that a decrease in demand for gasoline and an increase in demand for electricity cause a corresponding decrease in output in the oil industry and increase in output in the utilities sector. The extent of the decrease in output in the oil industry exceeds the increase in the output in the utilities sector. This can be attributed to the higher price of petroleum and higher efficiency of electric vehicles. In the event that the tax revenue collected by the government increases, it will be returned to the economy via government services in the "Other Services" sector.

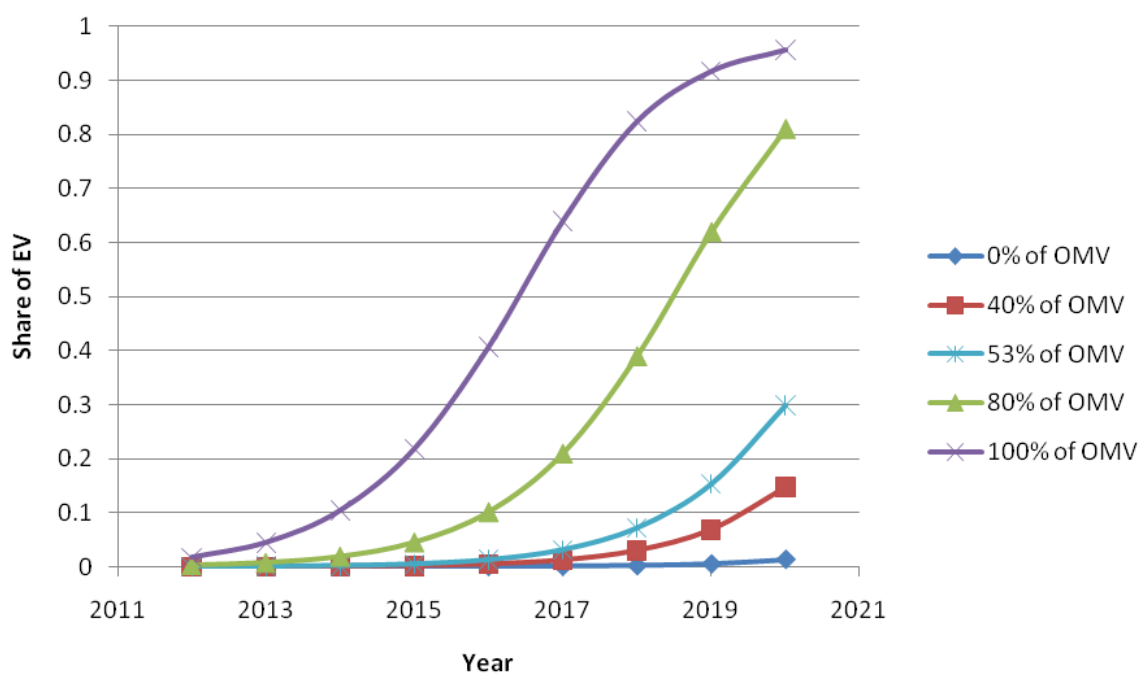

Fig. 1. Share of EV against time with different tax rebate rates 


\subsection{Effect of Carbon Tax}

Figure 2 shows that as the rate of carbon tax increases, the share of electric vehicles increases. The amount of carbon tax needed to reach an EV share of $30 \%$ is SGD $1.66 / \mathrm{kg} \mathrm{CO}$.

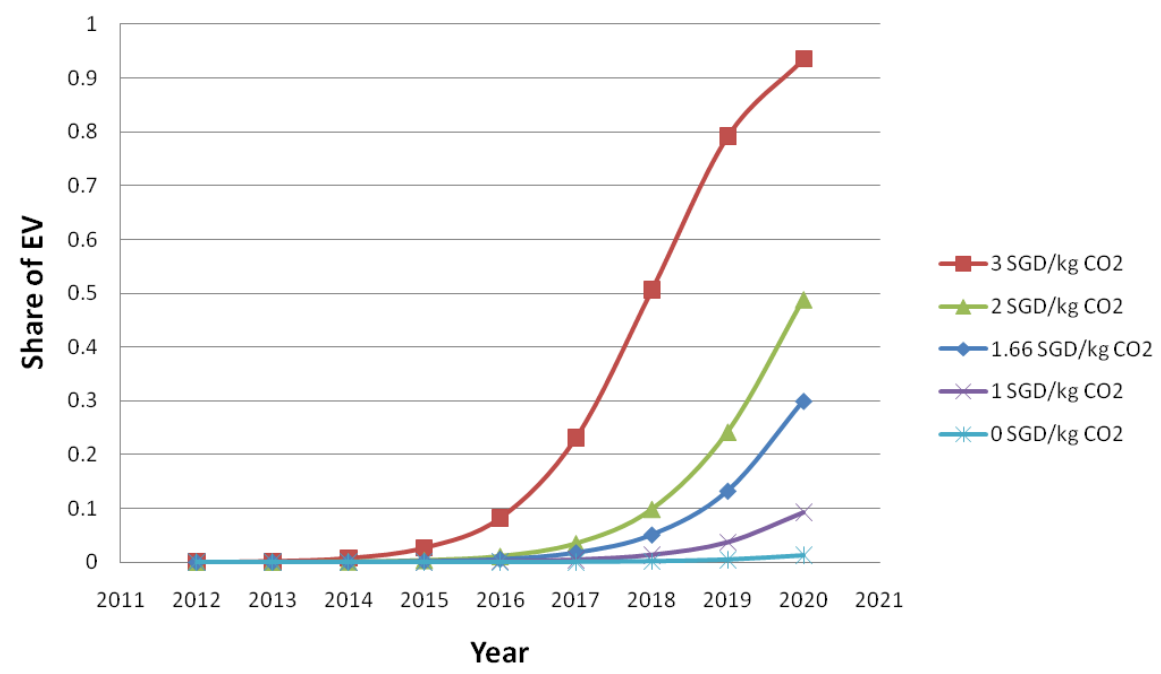

Fig. 2. Share of EV against time with different carbon tax rates

For determining the changes to the industrial structure, we assume that a higher overall cost of vehicles as a result of carbon taxation will cause a reduction in the total number of vehicles. This translates into the following changes to the industrial structure:

a) Reduction in final demand in the retail trade of motor vehicles

b) Reduction in final demand in the retail trade of automotive fuels (i.e., petrol kiosks and charging stations)

The changes to the industrial structure after the tax revenue is collected are redistributed back to the economy. Oil manufacturing and the retail trade industries register the largest dips in output, and other sectors show significant decreases in output not seen in case of a tax rebate. But note that the tax revenue collected increases as the tax rate increases.

\subsection{Economic Impact and Optimal Tax Rate}

It can be seen from Figure 3 that at lower levels of penetration of electric vehicles, a tax rebate mitigates the adverse effect on the economy, whereas at higher levels of penetration, the choice of a carbon tax results in a lower adverse impact on the 


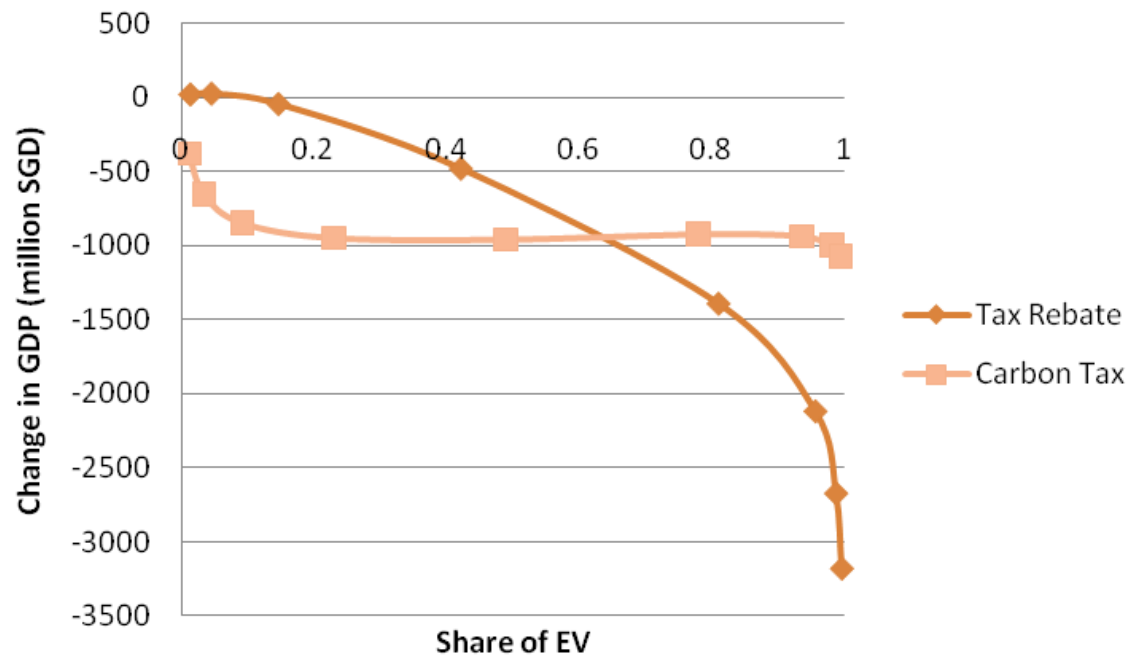

Fig. 3. Comparison of economic impact between tax rebate and carbon tax policies

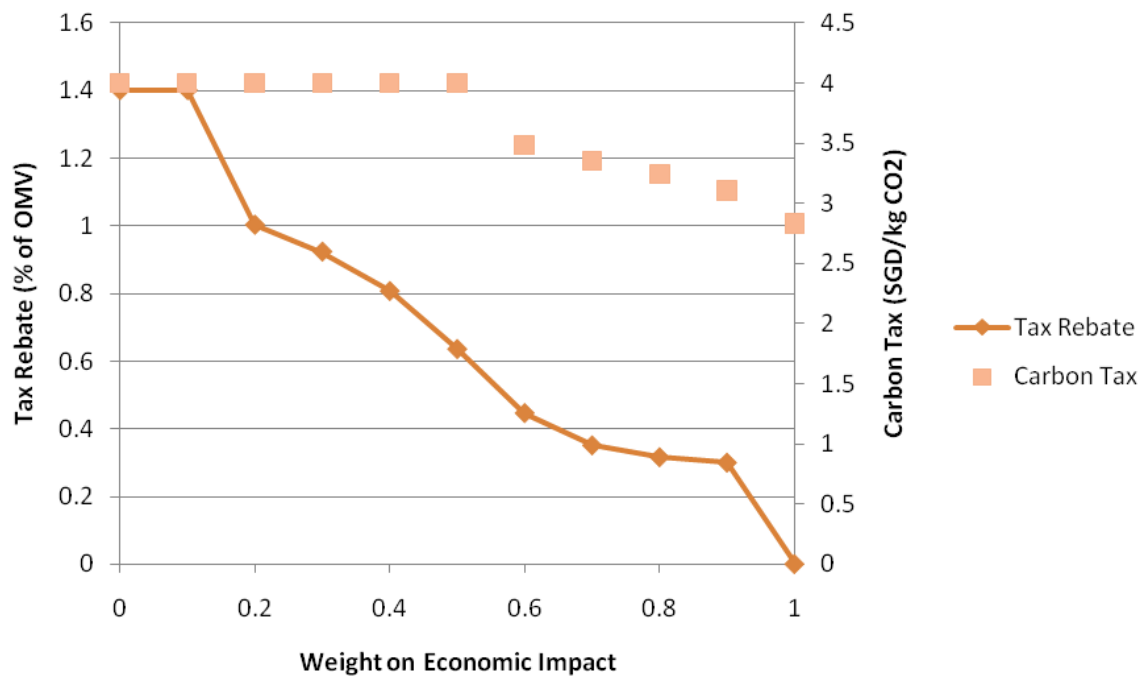

Fig. 4. Comparison of optimal tax rates

economy. This is because the carbon tax causes the total number of vehicles to decrease, which in turn results in a decline in the output of the retail trade of automobiles. However, the amount of tax rebate needed to effect a high penetration of electric vehicles causes a significant loss in tax revenues, whereas the increased tax revenue collected with the carbon tax mitigates the decrease in output of the economy as the share of electric vehicles increases. 
Figure 4 compares the optimal tax rates determined using multi-objective optimization described earlier. The optimal tax rates for both tax rebate and carbon tax decrease as the weight of their economic impact increases. This is because the higher the taxation, the larger the share of electric vehicles, and consequently, the lower the GDP because of decreased output in the petroleum industry.

Therefore, if the impact on the economy is of more importance, the optimal tax rate should be lower. Note that the optimal tax rates for a carbon tax are skewed toward the region of high values. This is because the gain in environmental benefit outweighs the drop in GDP as a result of an increase in the share of EVs, resulting in less of a need to lower the optimal tax rate even at higher weights of economic impact. In other words, the gain in environmental benefit at all shares of EVs is so significant that lowering the optimal tax rate will not result in substantial benefits from a smaller decline in GDP.

\section{Conclusion}

A tax rebate generally causes both the output of the economy and tax revenue to decrease, whereas a carbon tax causes the output to decrease and the tax revenue collected to increase. In terms of the impact on GDP, with tax revenue assumed to be returned to society, a tax rebate is found to be suitable at a low penetration of electric vehicles, while a carbon tax will minimize the adverse impact on the economy at higher adoption rates of electric vehicles, above $60 \%$ share. Therefore, a suggestion for the Singapore government is to first implement a tax rebate to kick-start the promotion of electric vehicles, before switching to a carbon tax when more electric vehicles start plying the roads.

With regard to environmental impact however, a carbon tax will cause a larger reduction in carbon dioxide than a tax rebate at every tax rate owing to a reduction in the total number of vehicles. A recommendation for the Singapore government is to opt for a carbon tax over a vehicle tax rebate if it intends to expedite the penetration of electric vehicles for their environmental benefits.

Acknowledgments. This work was supported in part by a Grant in Aid from the Global Center of Excellence Program for "Center for Education and Research of Symbiotic, Safe and Secure System Design" from the Ministry of Education, Culture, Sport, and Technology in Japan.

\section{References}

1. Nakano, M.: Challenges Facing Manufacturing to Move towards a Green Society with Clean Energy Vehicles. In: ElMaraghy, H.A. (ed.) Enabling Manufacturing Competitiveness and Economic Sustainability, pp. 434-438. Springer (2011)

2. Nakano, M.: A Conceptual Framework for Sustainable Manufacturing by Focusing on Risks in Supply Chains. In: Vallespir, B., Alix, T. (eds.) APMS 2009. IFIP AICT, vol. 338, pp. 160-167. Springer, Heidelberg (2010) 
3. Struben, J., Sterman, J.D.: Transition challenges for alternative fuel vehicle and transportation systems. Environment and Planning B: Planning and Design 35(6), 1070-1097 (2008)

4. Ueda, T., Muto, S., Morisugi, S.: An economic evaluation of automobile transport control measures that generate negative externalities. Transport Policy Research 1(1), 39-53 (1998)

5. Foo, T.S.: Urban Environmental Policy - The Use of Regulatory and Economic Instruments in Singapore. Habitat Intl. 20(1), 5-22 (1996)

6. Muthukrishnan, S.: Vehicle ownership and usage charges. Transport Policy 17, 398-408 (2010)

7. Olszewski, P., Turner, D.J.: New methods of controlling vehicle ownership and usage in Singapore. Transportation 20, 355-371 (1993)

8. Karplus, V.J., et al.: Prospects for plug-in hybrid electric vehicles in the United States and Japan: A general equilibrium analysis. Transport. Res. Part A (2010), doi:10.1016/j.tra.2010.04.004

9. Tokunaga, S., Muto, S., Huang, Y.H., Sun, L., Okiyama, M.: Modeling analysis of automobile environmental policy. Bunshindo (2008)

10. Nonaka, T., Nakano, M.: The Carbon Taxation by Using LCA including the Manufacturing Phase for Clean Energy Vehicles. In: M4SM Workshop. Euromaintenance 2010 Conference, Verona, Italy (2010)

11. Department of Statistics, Ministry of Trade and Industry, Singapore. Singapore InputOutput Tables 2005 (2010) 